\title{
Orofacial rare diseases: specificities of the collaboration between orthodontist and pediatric dentist
}

\author{
C. Ravinet ${ }^{1}$, P. Garrec ${ }^{2}$ \\ 1 AHU-PH - Odontologie pédiatrique, Université Paris-Diderot, Paris 7 \\ 2 MCU-PH - Orthopédie dento-faciale, Université Paris-Diderot, Paris 7
}

\section{ABSTRACT}

Pediatric dentistry plays an important part in the orthodontic treatment of patients with rare orofacial diseases. Interactions between these two disciplines are numerous and particularly noteworthy in the following pathologies:

- cleft lip and palate;

- ectodermal dysplasia;

- amelogenesis imperfecta;

- dentinogenesis imperfecta.

After reviewing the main characteristics of these pathologies, we will highlight the fundamental role of pediatric dentistry in the early diagnosis, the prevention and the dental care throughout the orthodontic treatment. A close cooperation between the orthodontist and the pediatric dentist is a key factor to a successful treatment.

\section{KEY WORDS}

Orthodontics preventive pediatric dentistry dentinogenesis imperfecta cleft palate interceptive

interdisciplinary approach

amelogenesis imperfecta corrective treatment ectodermal dysplasia cleft lip

\section{INTRODUCTION}

Orthodontic treatment for patients who present with malformations of the face and oral cavity caused by rare diseases is carried out by a multidisciplinary team.
A pediatric dentist (PD) is one of the major components of this team.

Orthodontic treatments increase the risk of the development of caries ${ }^{37}$. In addition 
to this inherent risk factor, there are other particularities of these patients that will have to be taken into account:

- clinical context:

- periodontal fragility (epidermolysis bullosa...);

- weakness of the enamel (amelogenesis imperfecta);

- specific physiological bone weakness and bone loss;

- general context:

- psychological factors (related to the handicap or to esthetics);

- oral hygiene habits necessary to learn to control plaque.

These atypical patients require the specialized clinical services of referral centers (centers for comprehensive care and diagnosis) but there are few of them and this limits the access that remote and rural populations have to care. One of the proposed solutions is the creation of city networks that draw from all the medical specialists, who then must learn to communicate and work together.
A recent study ${ }^{33}$ showed that $82.9 \%$ of orthodontists refused to treat patients who presented orofacial abnormalities in their offices.

The most commonly mentioned reasons for refusing treatment were the following:

- limited experience with this type of treatment;

- lack of expertise;

- lack of a multidisciplinary team.

Other reasons (the financial aspect, length of the treatment and lack of interest) were considered less important.

The authors conclude that additional time should be allocated in university and hospital curricula to training for these diseases.

Drawing from examples of pathologies encountered at the referral center, we will demonstrate how an orthodontist and pediatric dentist collaborate with one another.

- establish normal eating;

- improve pronunciation;

- enhance the psychological, social and emotional well being of the child and the family.

Esthetic and functional improvements for these patients consists in creating restorations utilizing the existing anterior teeth (Figs. 1 and 2) that are abnormally shaped (composite resin adhesives with direct or indirect technique, veneers, crowns) ${ }^{15}$ and in providing a prosthetic solution 

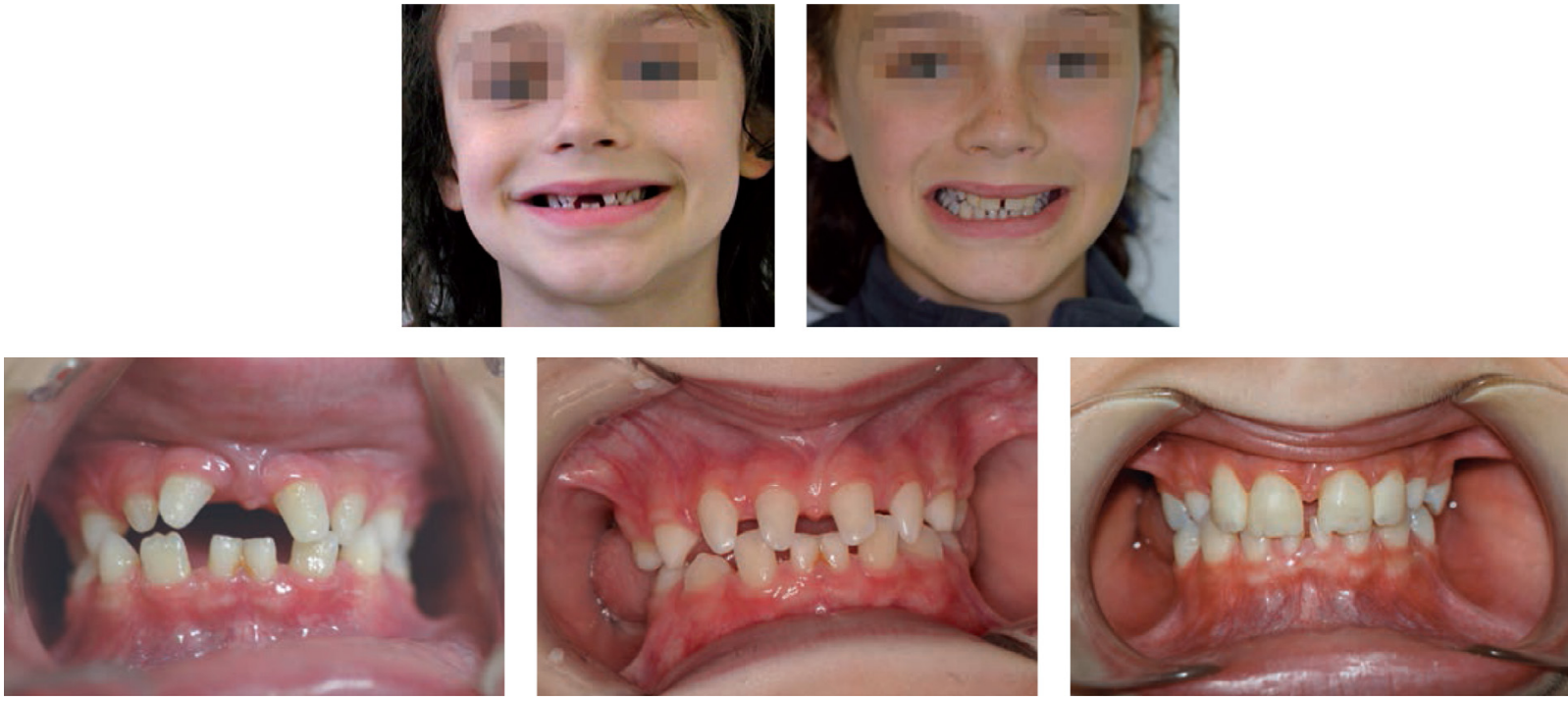

Figure 1

Patient who benefitted from simplified DFO treatment and restoration using composite bonding carried out at a laboratory (Dr Garrec/Dr De La Dure Molla) (MAFACE photos).
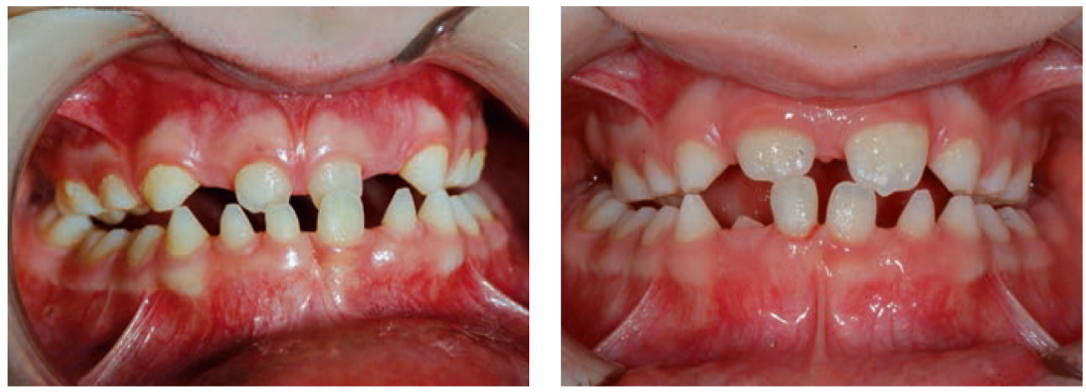

Figure 2

Creating a composite crown on 81 (agenesis of 41) for a patient in the first period of the mixed dentition with ED before orthodontic treatment (MAFACE documents).

whether permanently attached or removable (+/- supported and retained by symphyseal implants) ${ }^{22}$.

\section{Role of the pediatric dentist}

\section{Diagnosis}

An early diagnosis allows the practitioner to more effectively manage the treatment plan in the long term, and to restore confidence in patients by improving their self-image that can also be sometimes medically decisive: ectodermal dysplasia may also be part of a syndrome that involves a life-threatening diagnosis ${ }^{29}$.

Early detection of the presence of agenesis is of the utmost importance 


\begin{tabular}{|c|c|c|c|}
\hline & & Radiographic visibility & Clinical visibility \\
\hline \multirow{4}{*}{ Temporary dentition } & Incisors & Birth & 6-9 months \\
\hline & Canines & Birth & 18 months \\
\hline & $1^{\text {st }}$ molar & Birth & 12 months \\
\hline & $2^{\text {nd }}$ molar & Birth & 24 months \\
\hline \multirow{7}{*}{ Permanent dentition } & Central incisors & 6 months & $6-8$ years \\
\hline & Lateral incisors & 9-12 months & $7-9$ years \\
\hline & Mandibular canines & 6 months & $9-10$ years \\
\hline & Maxillary canines & 6 months & $11-12$ years \\
\hline & Premolars & $2-3$ years & $10-12$ years \\
\hline & $1^{\text {st }}$ molar & Birth & 6 years \\
\hline & $2^{\text {nd }}$ molar & 4 years & $11-13$ years \\
\hline
\end{tabular}

Table I

Approximate ages at which teeth may be detected either radiologically and clinically ${ }^{23}$.

in order to determine the final objectives of prosthetic restoration and to decide what implant site preparation is required to achieve it. Kupietzky ${ }^{23}$ developed a diagnostic chart that enables the practitioner to make an early diagnosis of congenitally missing teeth (Table I).

\section{Prevention}

For these patients, dental hygiene is generally rather good given the reduced number of teeth present to be cleaned and the gaps that allow for better brushing. The prevalence of caries appears to be insignificant, except for patients with xerostomia, who should be provided individualized preventive care: dental hygiene and dietary counseling as well as fluoride toothpaste.

It is important to preserve the integrity of the teeth present on the arch by sealing the grooves and providing essential conservative care ${ }^{34}$.

\section{Early treatment}

ED frequently causes severe psychological and social stress for these patients that tends to subside if they cooperate $^{31,35}$. The earlier the treatment begins, the more cooperative the child will be, because as the esthetics of the smile and masticatory function improve, he will feel more able to socially integrate and inevitably a sense of psychological well-being will follow. The failure to 
provide early treatment will have a harmful effect on the adolescent with physical, psychological and social ramifications ${ }^{43}$.

A lack of alveolar bone follows the absence of tooth buds and causes a significant loss of vertical height. An early prosthetic restoration will make it possible to maintain the height of the lower third of the face. The prosthesis will therefore need to be reassessed throughout the growth phase.

\section{Role of the orthodontist}

An orthodontic treatment may be necessary before the prosthetic restoration in order to manage the interdental spaces. This will often entail placing the permanent canines in the position where they belong. In fact, frequently the agenesis of the permanent upper premolars causes the canines to be located in a more distal position (Fig. 2b).

It might also prove to be useful for the practitioner to perform rapid maxillary expansion in order to establish functional prothetic relationships between the arches. (Fig. 3).

We observe root resorption on the central incisors during the course of orthodontic treatment more frequently in patients with oligodontia ${ }^{25}$. The orthodontist will have to be keenly aware of this and consult with the pediatric dentist in order to begin the appropriate pulpal therapy.

Treatment for patients with ectodermal dysplasia is complex and a multidisciplinary team will provide the best management plan ${ }^{19}$. The coordinated collaboration of the different disciplines makes it possible to achieve optimal results for the benefit of the patient ${ }^{34}$.

\section{CLEFT OF THE LIP ALVEOLUS AND PALATE (CLAP)}

\section{Charactistics}

Cleft lip and palate is one of most common congenital abnormalities with an incidence of 0.8 to $1 \%$ in France $^{6}$. The cleft can affect the lip, the alveolar bone as well as the hard and soft palate leading to esthetic, functional and psychosocial disorders $^{16}$. The diagnosis can be made with sonography during the $22^{\text {nd }}$ week of pregnancy.
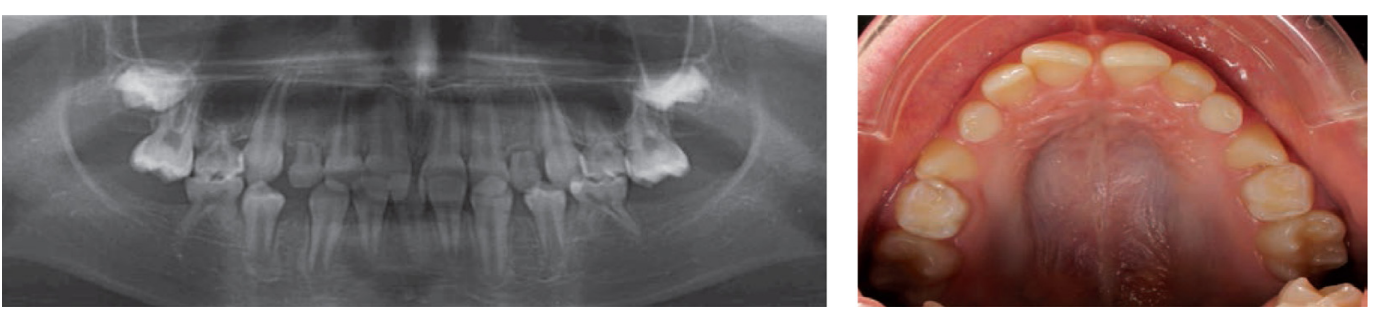

Figure $2 b$

Patient presenting agenesis of multiple teeth and the maxillary canines are distal to the primary canines (Dr. Garrec) (MAFACE documents). 

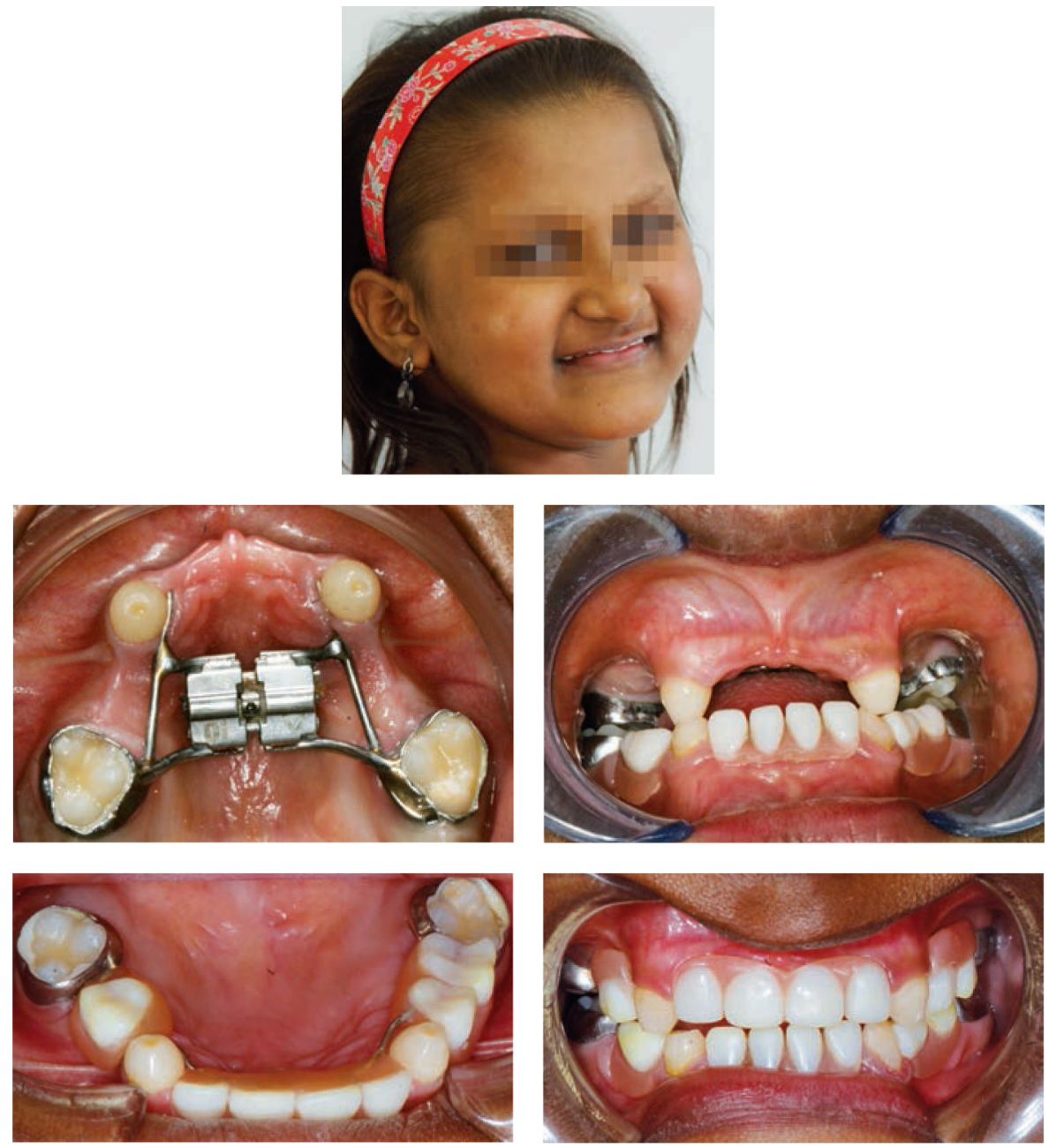

Figure 3

Patient presenting ectodermal dysplasia with severe oligodontia that requires maxillary expansion achieved with an expander on cemented brackets before restoration with a maxillary prosthesis (Dr. Ravinet) (MAFACE documents).

Therapeutic objectives $^{16}$ :

- early restoration of function and esthetics;

- facilitate normal eating;

- improve pronunciation;

- enhance the psychological, social and emotional well-being of the child and family;

These patients will be treated surgically soon after birth and then an ortho- dontic treatment appliance can be installed in the temporary or the mixed dentition in order to achieve transverse maxillary expansion necessary for the bone graft and in the permanent dentition to correct associated malocclusions. This complex and relatively long treatment needs to be managed by multidisciplinary team. 


\section{Role of pediatric dentistry ${ }^{16}$}

\section{Prevention}

Shortly after birth, counselors should encourage breastfeeding even though these new mothers may be reticent ${ }^{46}$. In spite of the problems that may be encountered and based on the type of cleft, breastfeeding is recommended for optimal craniofacial growth ${ }^{7}$. But when this is not possible, the practitioner should recommend latex orthodontic nipples (silicone nipples are less flexible and create ulcerations in the area of the cleft), with a 0.8 to $1 \mathrm{~mm}$ hole that makes it harder to extract milk therefore stimulating the orofacial musculature.

Bottlefeeding encourages the early introduction of sugar into the diet of infants. It is frequently introduced to promote weight gain that determines the timing for surgical intervention. Ideally, the first contact with sugar should be delayed as long as possible ${ }^{46}$.

Neonatal teeth are frequently observed in the area of the cleft $^{16}$ and it is important to extract them as soon as possible. These teeth are usually mobile and therefore places the infant at higher risk of inhalation given that there is communication between the oral and nasal cavities $^{8}$.

Studies are inconsistent about the risk of caries for these patients. According to Nivoloni Tannure ${ }^{31,32}$, there is no significant difference for the risk of caries compared with the general population, but Johnsen ${ }^{21}$ provides evidence showing a high risk of caries in the temporary dentition as does Dahllöf ${ }^{14}$ who found that patients with clefts had a higher significant caries index (sci) at 51/2 years.

The increased prevalence of caries might be explained by the special characteristics affecting the dental hygiene of these patients: anatomy around the cleft (Fig. 4) and dental abnormalities in the area of the cleft (of structure, of shape, of number, of position) ${ }^{27}$. In fact, according to Pegelow $^{38}$, there is an increase in the frequency of small teeth for cleft lip and cleft palate and increase in malformations of the lateral incisors for clefts of the lip and alveolus. Tooth enamel defects are significantly more common on the side of cleft in the primary and permanent dentition that particularly affects the permanent incisors $^{26}$. The dental enamel defect results from a disturbance in the development of the organic matrix and/ or of the mineralization process causing enamel hypoplasia +/- associated with a hypomineralization that has an esthetic impact and also increases the risk of secondary caries by fostering the buildup of plaque (Fig. 5).

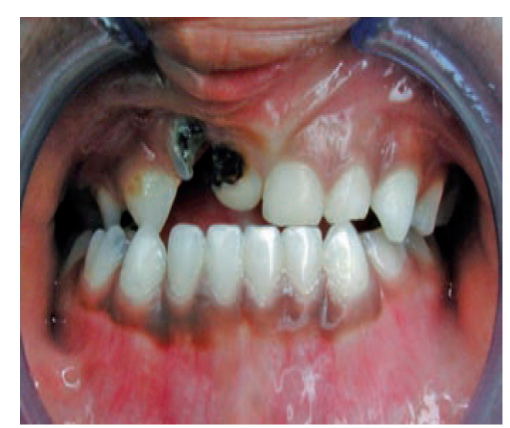

Figure 4

$6 \mathrm{yr}$ old patient with a right-sided unilateral cleft and carious lesions on the teeth bordering the edges of the cleft (52 and 51) (MAFACE documents). 


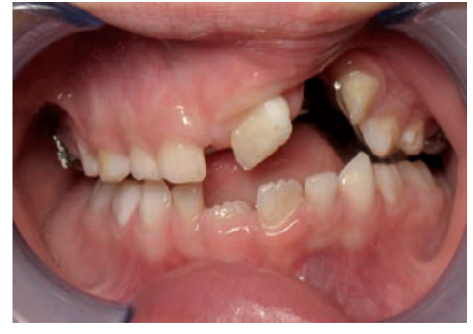

Figure 5

Weak enamel in the incisors bordering the cleft (MAFACE documents).

Compensatory overfeeding by the parents combined with poorer dental hygiene practices out of fear of touching the child's mouth may also explain why there are more caries ${ }^{9}$. Parents often have feelings of guilt about the baby's defect and since the infant has many operations, they are less vigilant about sugar intake because they want to make him "happy".

Therefore, it is important to inform the parents, to advise them about diet and dental hygiene. The first steps of good oral hygiene can start at birth by cleaning the soft tissues using a compress and sterilized water or saline solution. Brushing should begin as soon as the first teeth erupt, but prudence must be exercised and fluoride toothpaste should not be used before the age of 2 (ingesting excessive amounts leads to a risk of fluorosis).

Routine dental check-ups make it possible to monitor if oral hygiene is maintained, to remotivate the patient and to implement the necessary measures for prevention: applying fluoride, sealing the grooves, restoring the crowns of teeth presenting abnormalities in shape or structure.

\section{Specific therapeutic measures ${ }^{16}$}

Prior to surgery, it is crucial to make sure there are no signs of lesions or infections to ensure a successful intervention.

These patients and the general population use the same local anesthesia except in the area of the cleft. In this region, the maxilla is divided into different segments each with its own innervation, that persists even after the surgical repair ${ }^{47}$. A preoperative periapical xray is therefore necessary in order to analyze the bone site in which a tooth to be treated is located.

Surgery to repair the upper lip often causes fibroid scarring that makes the mucosa thicker and therefore an injection in this area is more painful.

It is advisable when making the infiltration to insert the needle parallel to the major axis of the tooth and then anesthetize adjacent regions. Anesthesia of the palate is absolutely imperative ${ }^{47}$.

Using the surgical site must be systematic when possible, especially with a palatal cleft that has not been surgically repaired. By doing this, dentists can avoid propulsing of water, carious debris and material from the restoration into the nasal cavity. It is very important to ensure the reliable stability of the rubber dam clamp and to secure it with a dental wire to avoid the risk of inhalation.

The treatments do not differ from those recommended for the general population and depend upon the severity of the carious lesion, and 

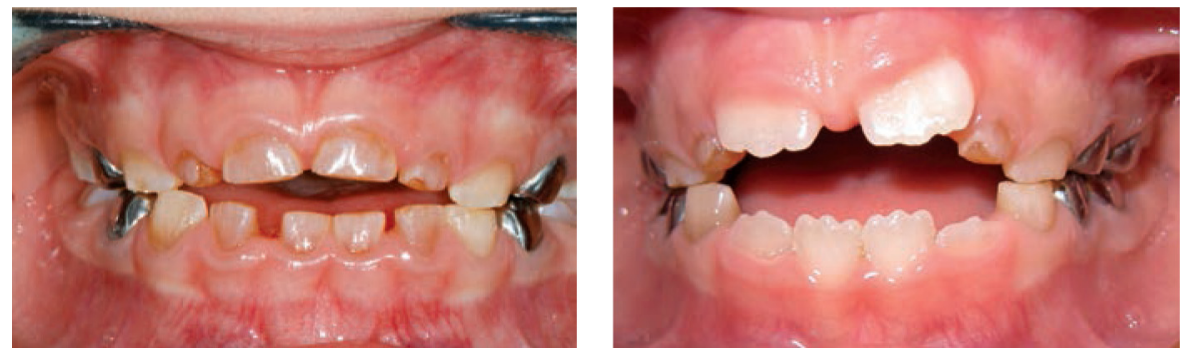

Figure 6

Dentinogenesis imperfecta: differential involvement of the two dentitions (MAFACE documents).

pulpal as well as periodontal involvement.

It is advisable to preserve the supernumerary primary teeth or teeth incorrectly positioned in the area of the cleft as long as possible in order to preserve as much bone mass as possible in this region.

\section{Role of the orthodontist}

(refer to the article of Brigitte Vi-Fane in this same issue)
Throughout treatment, the orthodontist should remain vigilant and should require that parents maintain a proper diet and good dental hygiene for the patient. The orthodontist should recommend regular follow-up with a pediatric dentist and should refer the patient if there is any hint of a carious lesion. The patient will benefit from their close collaboration.

\section{HEREDITARY DENTINOGENESIS IMPERFECTA (HDI)}

\section{Characteristics}

Dentinogenesis imperfecta is an abnormality of the dentin involving both dentitions, that most severely affects the primary dentition ${ }^{41}$ (Fig. 6).

Clinically, the teeth are globular, opalescent, the color ranges from blue-gray to yellow-brown. Radiographically, the roots are thin and we observe obliteration of the pulp chamber and the roots due to the excessive dentin production (Fig. 7).
With these patients, we encounter rapid wear and severe coronal attrition that leads to very obvious esthetic and functional consequences (Fig. 8).

\section{Therapeutic objectives:}

- esthetic and functional improvement;

- preservation of the coronal integrity;

- maintaining the vertical dimension of occlusion. 


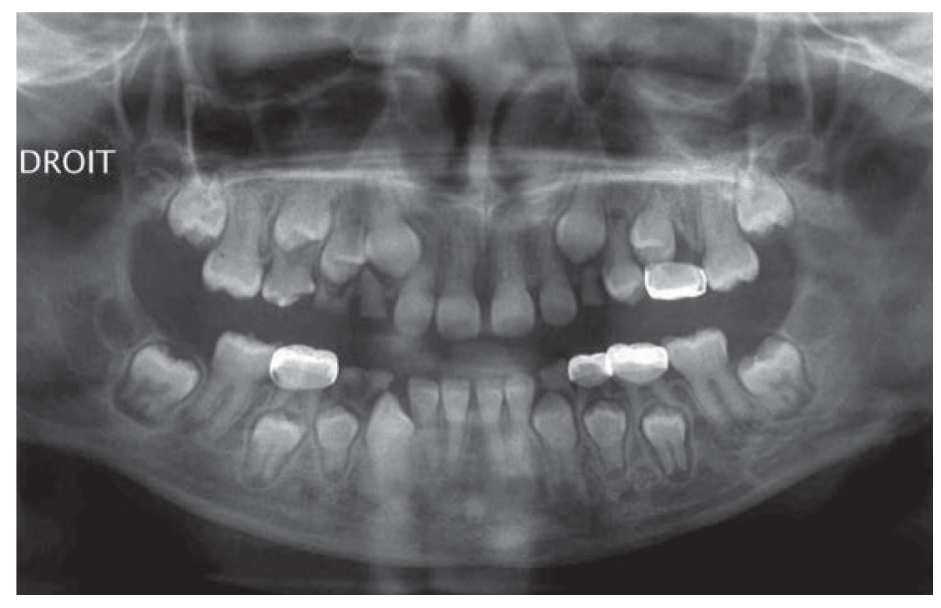

Figure 7

Radiographic appearance of dentinogenesis imperfecta (MAFACE documents).

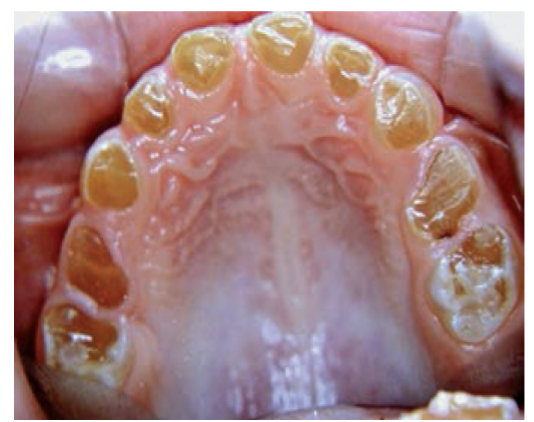

Figure 8

Rapid and severe coronal wear in a patient with dentinogenesis imperfecta (MAFACE documents).

\section{Role of pediatric dentistry}

\section{Diagnosis}

The diagnosis can be made very early (Fig. 9).

When dentinogenesis imperfecta is associated with osteogenesis imperfecta (Shields type 1), the practitioner can make a differential diagnosis with a case of physical abuse where a child presents multiple bone fractures ${ }^{50,51}$.

\section{Prevention}

These patients have the same risk for caries as the general population. We have not observed any tooth or soft tissue tenderness in these patients, even in cases of severe attrition.

However, there is a higher frequency of the appearance of apical lesions without a carious portal ${ }^{1}$. Since hypomineralization of the dentin makes root canal impossible (risk for false pathways, perforations), extraction becomes inevitable. Regular radiographic follow-up visit will be necessary in order to avoid complications related to the development of an apical lesion (Fig. 10). After extraction, a space maintainer is generally installed. Even in a Shields type 1, bone healing is successful. 


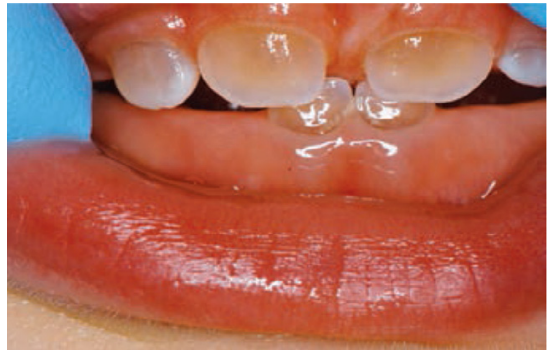

Figure 9

Early diagnosis of dentinogenesis imperfecta (curtesy of Dr. Naulin-Ifi).
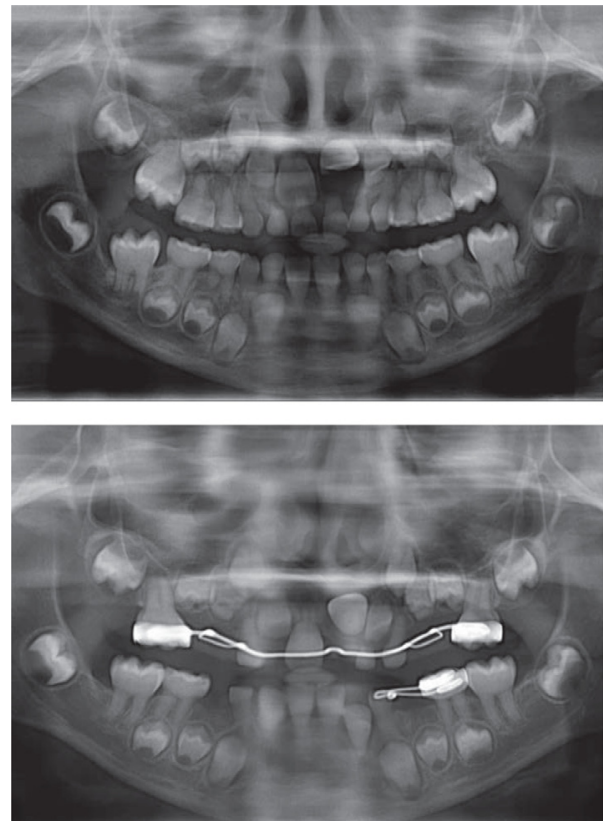

Figure 10

Panoramic xray of a patient with an unerupted tooth bud on 22 following the development of an apical lesion on 61. The extraction of 61 prevented the correct guidance of 21 that had rotated in the direction of the nasal floor (MAFACE documents).

\section{Early treatment ${ }^{40}$}

There is a variability of clinical expression for this pathology and consequently with many degrees of severity relating to wear and dyschromia. Therapeutic choices have to be made accordingly.

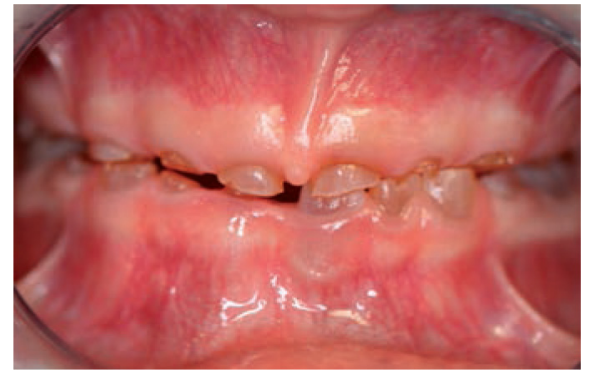

Figure 11

Loss of Vertical Dimension of Occlusion in a patient with dentinogenesis imperfecta (MAFACE documents).

The earlier the treatment begins, the better the therapeutic prognosis will be. The loss of vertical dimension (Fig. 11) is not associated with a decrease in the height of the lower face: compensatory bone formation occurs. On the other hand, the prosthetic space is reduced. By increasing the vertical dimension, prosthetic restoration therefore runs the risk of creating a modification of the facial outline.

Esthetic and functional restoration in the temporary and the mixed dentitions can be achieved with full-coverage therapy ${ }^{1}$. In consists of placing preformed metallic crowns on the temporary and permanent molars and composite crowns using the indirect technique on the temporary incisors and canine area to achieve better adhesion and a reliable esthetic result. Restoration of the permanent incisors will be determined based on its esthetic impact. Carbamide peroxide bleaching of teeth appears to provide satisfying esthetic results $^{13}$.

When the loss of vertical dimension is already severe with total obliteration of the crowns, the prosthetic 
restoration will consist of a single prosthesis that overlays the complete dentures ${ }^{1}$.

\section{Role of the orthodontist}

We observe an increased incidence of Class III malocclusions in patients with dentinogenesis imperfecta (when combined with osteogenesis imperfecta) (Figs. 12 and 13), with a significant frequency of molar crossbite with a posterior open bite for Shields type $1^{36}$. Orthodontic treatment is almost automatically required.

Since the frequency of the appearance of root resorption during orthodontic treatment is greater in these patients, the orthodontist must be particularly vigilant and the patient should be referred to a pediatric dentist in order to begin appropriate treatment of the dental pulp. The duration of the active treatment will also be decreased and ortho-surgical procedures should be planned ahead of time.
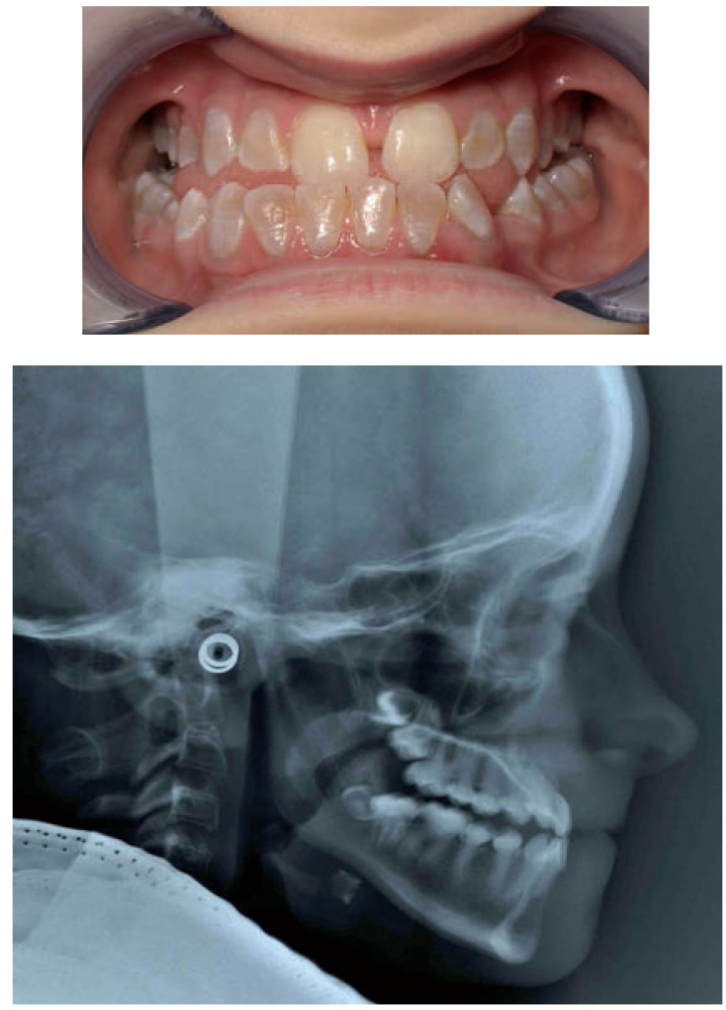

Figures 12 and 13

Dental and skeletal Class III llateral cephalometric xray) in a young patient presenting dentinogenesis imperfecta associated with osteogenesis imperfecta (Shields type 1) (MAFACE documents).

\section{HEREDITARY AMELOGENESIS IMPERFECTA (HAI)}

\section{Characteristics}

Hereditary amelogenesis imperfecta is a genetic defect of the enamel that has a wide variability of clinical expression. This abnormality affects both dentitions with the same degree of severity but its clinical expression can vary from one patient to another.

The enamel is altered from a qualitative and/or quantitative perspective and there are three clinical forms: hypoplastic, hypocalcified and hypomaturation (Fig. 14). These different clinical phenotypes will affect our choice of therapy in different ways ${ }^{10}$.

\section{Therapeutic objectives ${ }^{24}$ :}

- to manage the tenderness (HAl hypocalcified);

- to prevent coronal attrition and restore the occlusion (HAl hypoplastic and hypocalcified);

- to decrease retention of plaque (HAl hypoplastic and hypocalcified);

- maintain the periodontal health $(\mathrm{HAl}$ hypocalcified); 


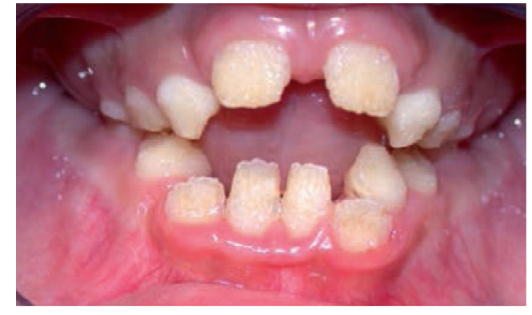

a

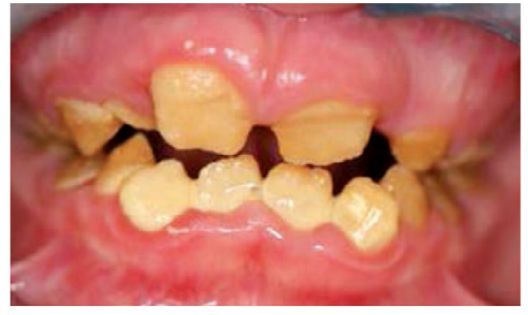

b

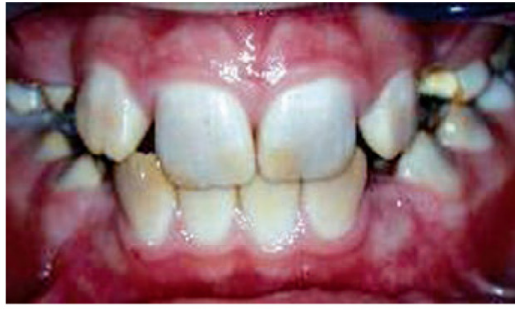

C

Figure 14

(a) H.A.I. Hypoplastic; (b) H.A.I. Hypocalcified; (c) H.A.I Hypomaturation (MAFACE documents).

- restore the esthetics;

- treat associated malocclusions;

- promote the psychosocial wellbeing of the patient ${ }^{11}$.

\section{Role of the pediatric dentistry}

\section{Diagnosis}

An early diagnosis is important because the patient can then be advised to seek genetic counseling and can be referred to specialized centers where the therapeutic management will be better ${ }^{41}$.

A diagnosis of the clinical phenotype is also very useful. It makes us aware of the tooth sensitivities that the patient might be experiencing, the periodontal difficulties that will be encountered as well as other characteristics that might have a direct link to the orthodontic treatment such as adhesion to the enamel, the associated malocclusions, delayed or failed eruption.

When the practitioner is faced with the hypoplastic type of $\mathrm{HAl}$ with impacted teeth, he must be aware of the associated risk for nephrocalcinosis, warn the patient and refer him to a nephrologist who can perform a base line renal sonogram. Early treatment management for nephrocalcinosis has a very good prognosis. The diagnosis must be made as soon as possible.

\section{Prevention}

Patients with HAl have a low risk for caries $^{39,48}$ but often have problems with dental and oral hygiene ${ }^{10,28}$ and often present excessive tarter, gingival inflammation and associated periodontal problems ${ }^{39,45}$. The surface roughness of the teeth fosters the buildup of dental plaque and tooth sensitivities make the child feel apprehensive about brushing ${ }^{28}$.

From very early on, the dentist should give dietary advice and oral and dental hygiene guidance in order to limit the tooth sensitivities, protect the already fragile enamel and preserve the periodontium. Going over these guidelines should be done on a regular basis to promote patient cooperation and to invigorate patient motivation, which is so essential for effective therapeutic management.

To prevent oral sensitivities, the practitioner should apply numbing toothpaste, and should recommend brushing with lukewarm water ${ }^{27}$, a numbing toothpaste, a mouthwash with $0.5 \%$ sodium fluoride and a weekly application of fluoride gel or 
paste. These preventive measures strengthen resistance to demineralization, significantly reduce tooth sensitivities, and foster enamel remineralization and post-eruptive maturation $^{2}$. It should also be pointed out that a daily application of casein phosphopeptide combined with amorphous calcium phosphate (CPP-ACP) that makes it possible to accelerate remineralization, to harden the enamel, to reduce enamel demineralization, decrease oral sensitivities and to improve esthetics ${ }^{17}$.

Using a surgical dam also allows the surgeon to protect the non-treated teeth (therefore unanesthetized) from thermal damage.

Early management of tooth sensitivities will provide comfort to the patient but will also promote better adhesion and more esthetically pleasing restorations in a healthy gingival environment ${ }^{28,30}$. In addition, sensitivities often give rise to anxious behavior towards treatment that can further complicate the management of these patients ${ }^{28}$.

We observe rapid wear of the teeth in patients who have $\mathrm{HAl}^{39}$. Therefore, it is important to preserve the coronal integrity as soon as possible in order to limit the loss of vertical dimension and of arch length. Coronal restorations with complete coverage are a good way to achieve this in the primary dentition and in the immature permanent dentition, thus providing esthetic enhancement as well as a reduction in sensitivities $^{30}$. Moreover, these restorations are recommended as soon as the proximal surfaces are affected ${ }^{41}$.

\section{Esthetic and conservative treatments}

In mild cases of HAl (especially for the hypoplastic forms), a classic composite restoration can be fabricated using the direct technique. Esthetics and plaque control will both be improved, since the enamel surface will now be smoother.

In cases where the damage is more severe (especially for the hypomineralized forms), it is advisable to plan for total restoration with ceramic crowns ${ }^{12,45}$ using the preformed pediatric composite crowns, composite crowns by the indirect technique, a polycarbonate temporary crown, composite or ceramic veneers.

\section{Posterior areas}

Generally, it is advisable to seal/ bond the preformed pediatric crowns (PPC) on the temporary and permanent molars as soon as possible (Fig. 15). Placement is simple and rapid, their cost is still moderate and their long term resistance is reliable over time. They can be installed with no prior preparation of the tooth. Orthodontic separators (rings) can be placed a few days before to avoid preparing the proximal surfaces ${ }^{45}$. Therefore, it is possible to preserve the integrity and the vitality of the tooth by reducing tooth sensitivities and to foster improved oral and dental hygiene. The proximal and occlusal relationships can be correctly established, the vertical dimension and arch length are maintained and function is improved. Placement of a PPC also makes it easier to install orthodontic brackets with no risk to 

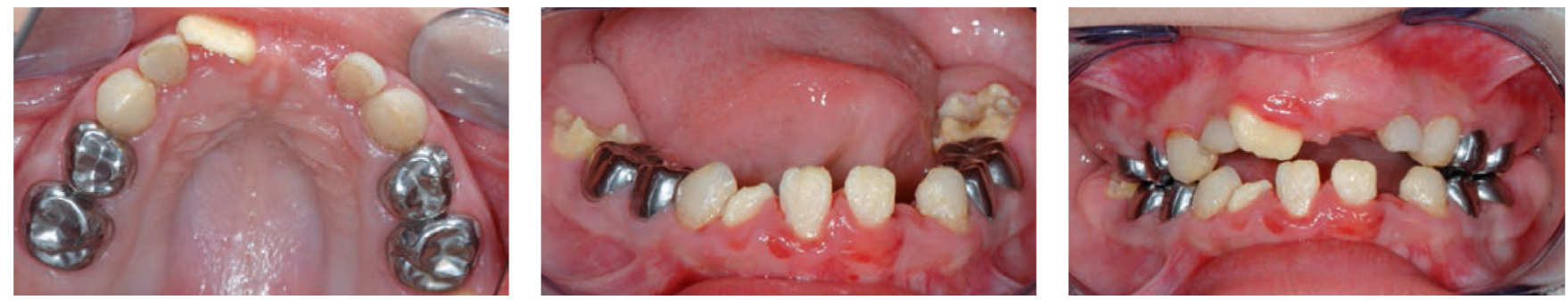

Figure 15

Placement of a SSC (Stainless Steel Crown) on the temporary molars of a patient with H.A.I. (Dr De La Dure Molla) (MAFACE documents).

the teeth. In cases where eruption is delayed, a surgical exposure followed by the placement of a PPC will be necessary.

Bonding with glass ionomer cement is recommended due to the reuptake of fluoride that increases resistance to the formation of secondary caries and reduces tooth sensitivity to heat, especially in severe cases of hypomineralized $\mathrm{HAl}^{41}$.

For patients with extensive esthetic enhancement requests, composite crowns fabricated in the laboratory can provide a good compromise, as is the case with the anterior teeth. However, their fabrication requires a greater occlusal thickness than a CPP has. It is recognized that an overbite of $\leq 3 \mathrm{~mm}$ spontaneously realigns within a period of three months ${ }^{18}$, that may make us decide not to prepare the teeth. This must be balanced against the risk of worsening the anterior gap, frequently present in these patients. The decision will be made in consultation with the orthodontist. Early shrinkage of the pulpal horns in the teeth affected by HAl requires a minimal preparation for younger patients $^{41}$, that may also provide a compromise in certain cases.

\section{Anterior teeth}

Veneers or composite crowns using the indirect technique should be fabricated on the temporary teeth (Fig. 16) and immature permanent
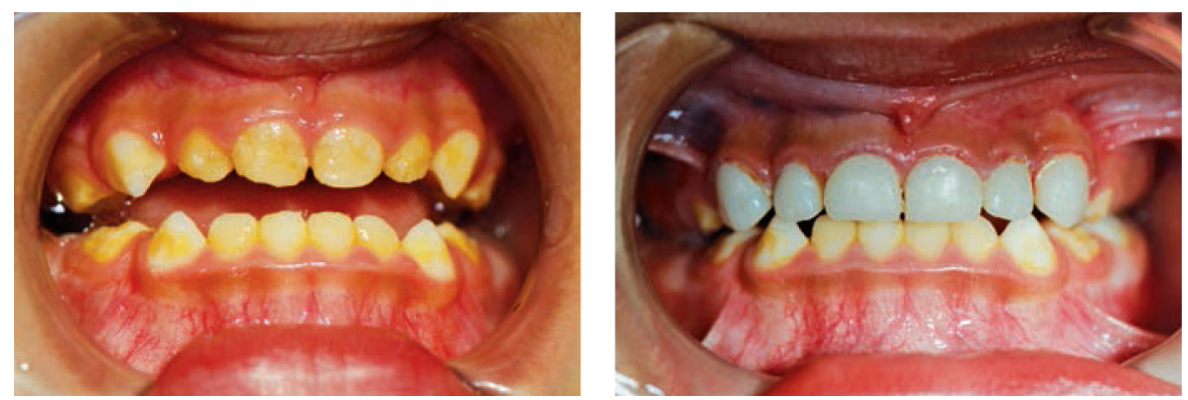

Figure 16

Anterior restoration in the temporary dentition in a patient with HAl using composite crowns fabricated in the laboratory without prior preparation (courtesy of Dr. Naulin-Ifi). 

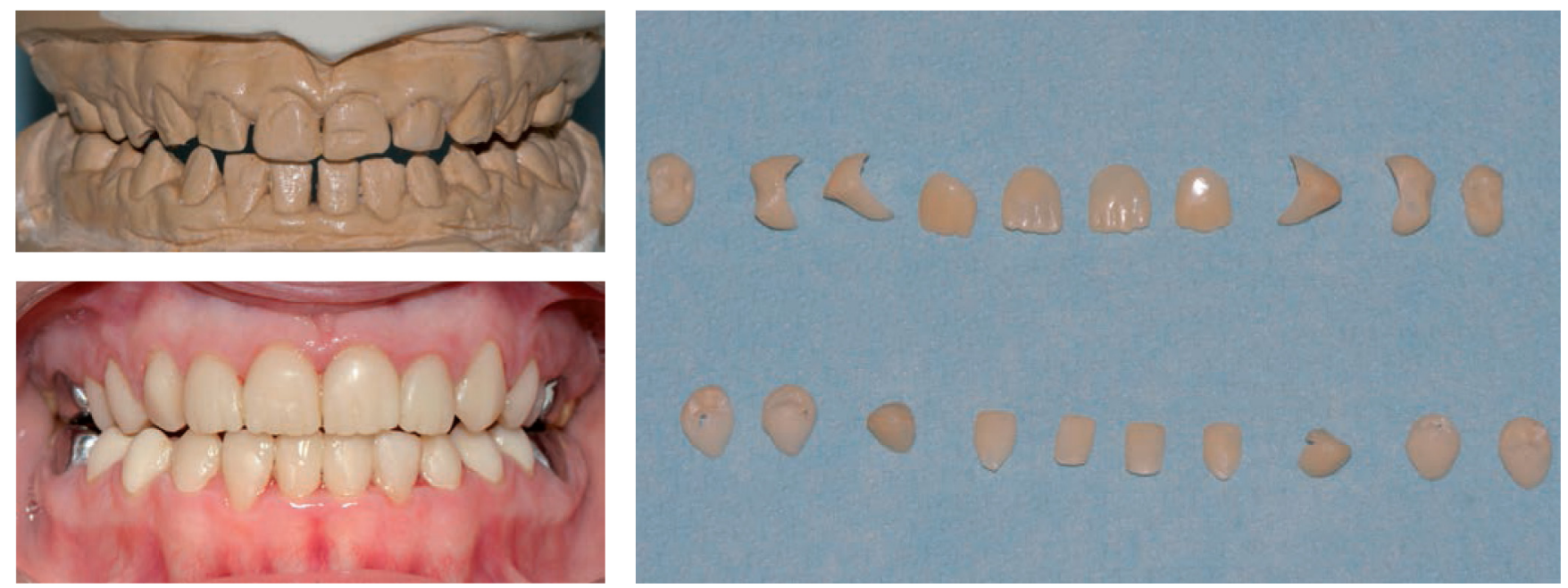

Figure 17

Example of restoration in the dentition of a young adult after orthodontic treatment in a patient presenting HAI (Dr. De la Dure Molla) (MAFACE documents).

teeth (Fig. 17) for severe forms, without prior preparation. They may be sealed with $\mathrm{CVI}$ or bonded with bonding cement ${ }^{41}$. This method requires two visits and some cooperation from the child but it will allow the practitioner to fabricate an entire sector in a minimum of time if compared with the fabrication of composite crowns using the direct technique. The use of invisible aligners can shorten the process of fabricating the composites using the direct technique with a good esthetic result but their long term stability is not as good as that of composite crowns fabricated in a laboratory ${ }^{10,41}$. The financial cost is higher but the result is much more pleasing in regard to esthetics, function and long term reliability.

In cases of hypomaturation $\mathrm{HAl}$ with mild esthetic impact, bleaching and microabrasion should provide a satisfying solution that costs less and reduces tissue loss ${ }^{4}$.

At the end of orthodontic treatment, veneers or ceramic crowns will be a more esthetic and more durable solution for the patient that will reduce the build up of tartar.

\section{Some specifics relative to orthodontic care and treatment}

Bonding orthodontic brackets for these patients represents a real challenge for the practitioner. In fact, $\mathrm{HAl}$ is characterized by an increase in the protein matrix and a decrease in the mineralized matrix of the enamel responsible for the lack of adhesion of the enamel ${ }^{44,52}$.

Hypomineralized HAl has the lowest ratio of mineralized matrix volume with a significant increase of protein whereas hypoplastic HAl has a slightly higher ratio of proteins than that of 

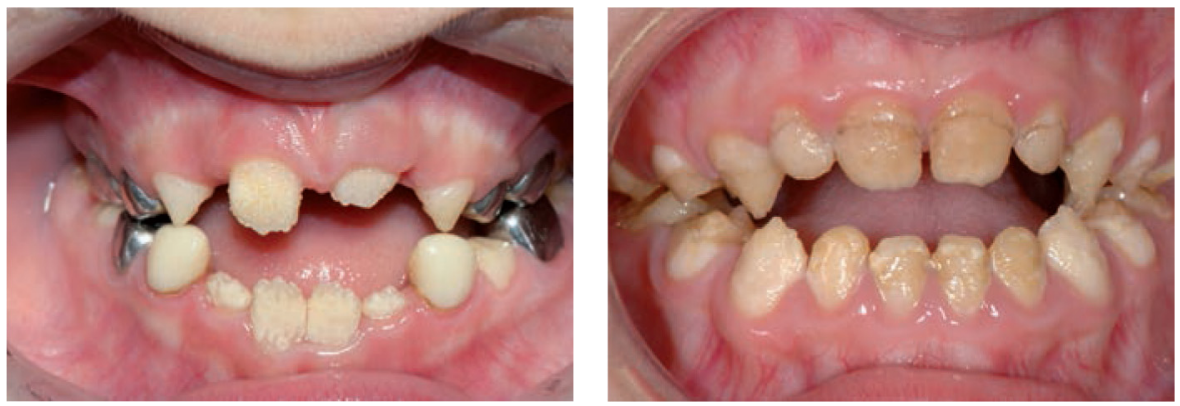

Figure 18

Lack of incisor overlap in patient with H.A.I (MAFACE documents).

healthy enamel. The adhesion of the composite resins on hypomineralized enamel is significantly worse than on healthy enamel ${ }^{20}$.

An accurate reading of an xray allows the practitioner to assess the thickness of the enamel and consequently to anticipate problems with bonding ${ }^{12}$.

A clinical diagnosis then directly influences the choice of protocol for bonding to the enamel for preventive care and bonding of orthodontic brackets.

A pretreatment of the enamel with $5 \%$ sodium hypochlorite make it possible to degrade the protein matrix and therefore enhances bonding $^{42,49,53}$. Next, it is advisable to use self-etching adhesives rather than traditional etching with phosphoric acid that causes loss of enamel and is consequently responsible for inferior adhesion ${ }^{41}$.

Teeth affected by hypomineralized HAl show a loss of post-eruptive enamel surface (secondary hypoplasias) leading to exposed dentin. The use of dentin adhesives or placement of glass ionomer cement before the composite restoration helps to minimize the risk of adhesion failure ${ }^{45}$.
HAl may be associated with gingival hyperplasia ${ }^{39}$ that requires periodontal surgery in order to prepare the teeth for care and for bonding of orthodontic brackets.

\section{Influence of $\mathrm{HAl}$ on orthodontic treatment management}

We observe a greater prevalence of the lack of incisor overlap (incisor open bite) in patients presenting $\mathrm{HAl}$ : $60 \%$ for hypomineralized $\mathrm{HAl}$ and $50 \%$ for hypoplastic HAl and $31 \%$ for hypomaturation $\mathrm{HAl}^{3}$. This gap will have to be taken into account in the assessment of difficulty of orthodontic treatment (Fig. 18) and will require surgery to compensate for this opening in certain cases (Fig. 19).

HAl may be accompanied by delayed or failed eruption (Fig. 20) and agenesis, and they all have a direct impact on orthodontic treatment management ${ }^{30}$.

Early multidisciplinary treatment management improve the prognosis of the treatment in the long run $^{5}$ and obviously enhances the psycho-social well being of the patient ${ }^{1}$. 

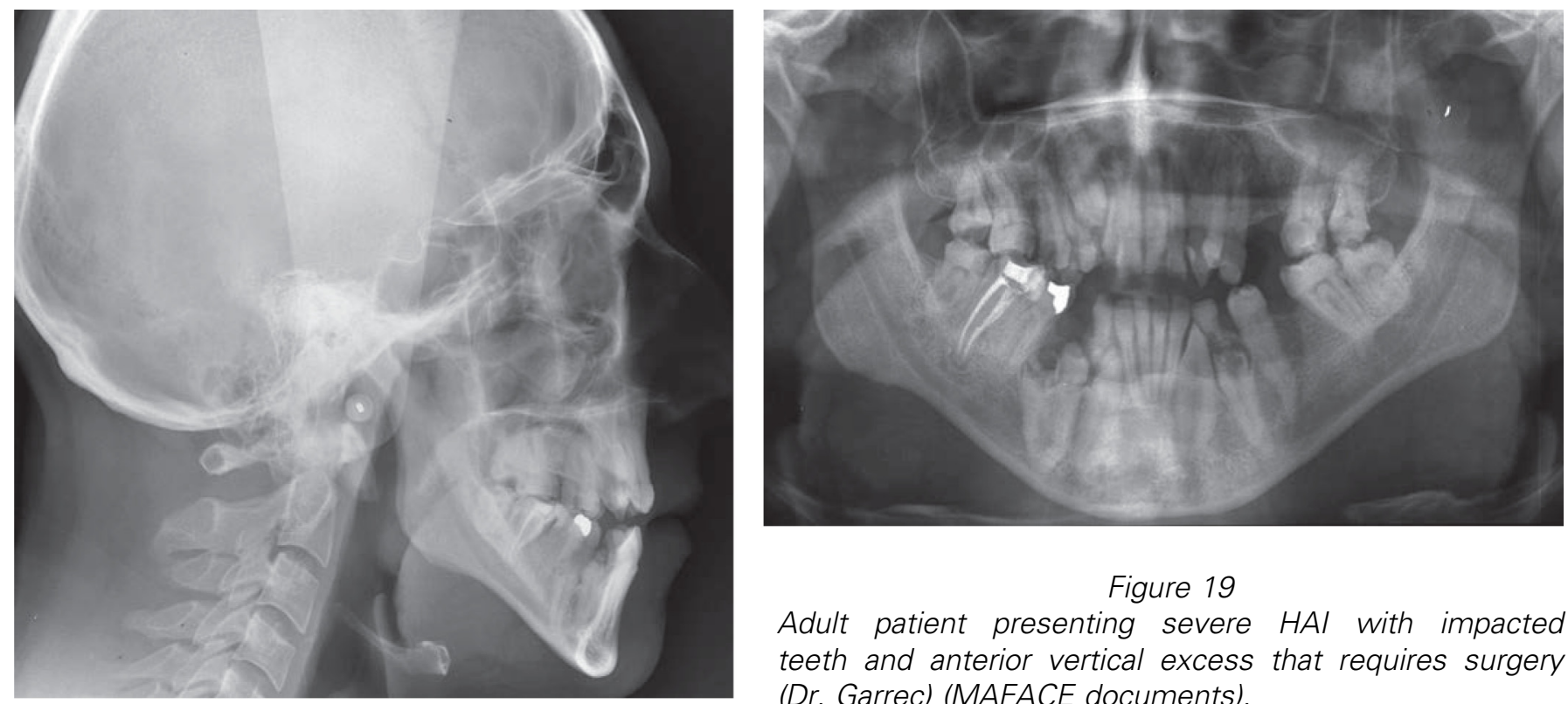

Figure 19

Adult patient presenting severe HAl with impacted teeth and anterior vertical excess that requires surgery (Dr. Garrec) (MAFACE documents).

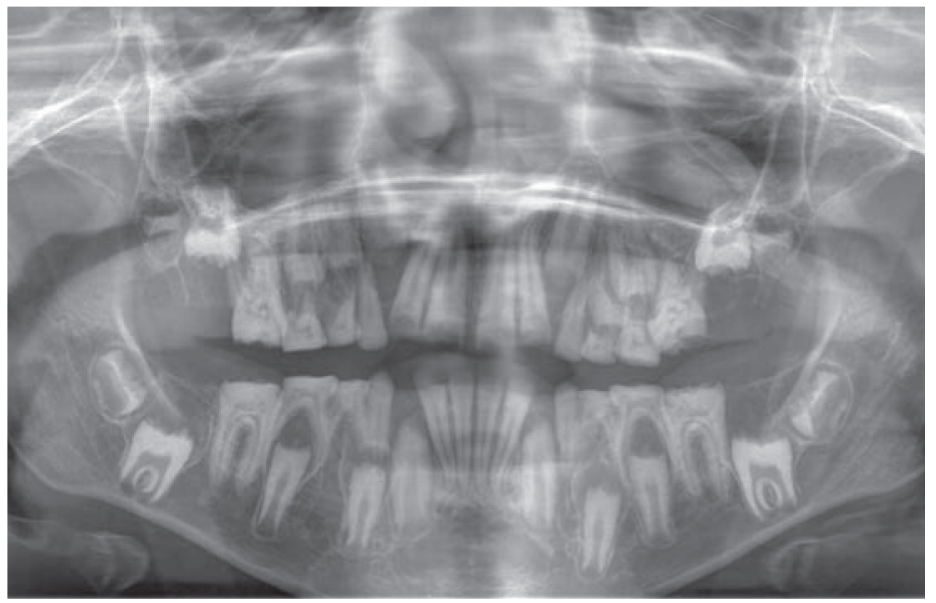

Figure 20

Delayed or failed eruption in a patient presenting severe HAI (Dr. Garrec/Dr. De La Dure Molla) (MAFACE documents).

\section{CONCLUSION}

Pediatric dentistry is one of the indispensable components in a multidisciplinary team that cares for patients with rare orofacial diseases.
It intervenes on different levels: diagnosis, prevention, oral treatments, follow-up and reassessment of oral and dental procedures during 
the comprehensive treatment of these patients. Early treatment, regardless of the pathology, is indispensable in order to plan a long term esthetic and functional solution and to enhance the psychological and social well-being of the patient and the family. A pediatric dentist provides valuable assistance to the orthodontist by reducing the complexity of certain cases and by encouraging greater cooperation from the patient.

\section{BIBLIOGRAPHY}

1. AAPD 2008 Guidelines on oral health care/dental management of heritable dental developmental anomalies.

2. Adair SM. Evidence-based use of fluoride in contemporary pediatric dental practice. Pediatr Dent 2006;28:133-42.

3. Aren G, Ozdemir D, et al. Evaluation of oral and systemic manifestations in an amelogenesis imperfecta population. J Dent Res 2003;31(8):585-91 .

4. Ashkenazi $M$, Sarnat $H$. Microabrasion of teeth with discoloration resembling hypomaturation enamel defects: 4 year follow-up. J Clin Pediatr Dent 2000;25:29-34.

5. Ayers KM, Drummond BK, Harding WJ, et al. Amelogenesis imperfect: multidisciplinary management from eruption to adulthood. N Z Dent J 2004;101-4.

6. Bénateau H, Taupin A, Ory L, Compère J.-F. Généralités sur les fentes labio-alvéolopalato-vélaires (hors prise en charge). EMC - Stomatologie 2012;7(3):1-23 [Article 22-066-A-50].

7. Bessel A, Hooper L. et al. Feeding interventions for growth and developmental in infants with cleft lip, cleft palate or cleft lip and palate. Cochrane Database Syst Rev 2011;16;(2):CD003315.

8. Cabete HF, Gomide MR, Costa B. Evaluation of primary dentition in cleft lip and palate children with and without natal/neonatal teeth. Cleft Palate Craniofac J 2000;37(4):406-9.

9. Castilho A. et al. Evaluation of oral health knowledge and oral health status in mothers and their children with cleft lip and palate. Cleft Palate-Craniofacial $J$ 2006;43(6):726-730.

10. Chen CF, et al. Assesment of restorative treatment of patients with amelogenesis impefecta. Pediatr Dent 2013;35:337-42.

11. Coffield KD, et al. The psychosocial impact of developmental defects in people with hereditary amelogenesis imperfecta: a report of two cases. J Dent Child 1996;63:443-7.

12. Collins MA, Mauriello S, et al. Dental anomalies associated with amelogenesis imperfecta: a radiographic assesment. Oral Surg Oral Med Oral Pathol Oral Radiol Endod 1999:88:358-64.

13. Croll TP, Sasa IS. Carbamide peroxide bleaching of teeth with dentinogenesis imperfecta. Discoloration: Report of a case. Quintessence Int 1995;26:683-6.

14. Dahllöf G, Ussisoo-Joandi R, Ideberg M, Modeer T. Caries, gingivitis, and dental abnormalities in preschool children with cleft lip and/or palate. Cleft Palate $\mathrm{J}$ 1989;26(3):233-7.

15. Ellis RK, Donly KJ, Wild TW. Indirect composite resin crowns as an esthetic approach to treating ectodermal dysplasia: a case report. Quintessence Int 1992;23(11):727-729.

16. Freitas JA, et al. Rehabilitative treatment of cleft lip and palate: experience of the hospital for rehabilitation of craniofacial anomalies - part 2: pediatric dentistry and orthodontics. J Appl Oral Sci 2012;20(2):268-81. 
17. Giniger M, MacDonald J, Ziemba S, et al. The clinical performance of professionnally dispensed bleaching gel with added amorphous calcium phosphate. J Am Dent Assoc 2005; 136:383-92.

18. Harley KE, Ibetson RJ. Dental anomalies: are adhesive castings the solution? Br Dent J 1993;174:15-22.

19. Hobkirk JA, Nohl F, et al. The management of ectodermal dysplasia and severe hypodontia. International conference statements. J Oral Rehab 2006;33:634-637.

20. Hosein I, Sheriff M, Ireland AJ. Enamel loss during bonding, debonding and clean up with use of a self-etching primer. AM J Othod Dentofacial Orthop 2004;126:717-24.

21. Johnsen DC, Dixon M. Dental caries of primary incisors in children with cleft lip and palate. Cleft Palate J 1984;21:104-109.

22. Kotsiomiti E, Arapostathis K, Kapari D, Konstantinidis A. Removable prosthodontic treatment for the primary and mixed dentition. J Clin Pediatr Dent 2000;24:83-89.

23. Kupietzky A, Houpt M. Hypohidrotic ectodermal dysplasia: characteristics and treatment. Quintessence Int 1995;26:285-291.

24. Kwok-Tung L, King NM. The restorative management of amelogenesis imperfecta in the mixed dentition. J Clin Pediatr Dent 2006;31:130-5.

25. Levander E, Malmgren O, Stenback K. Apical root resorption during orthodontic treatment of patients with multiple aplasia: a study of maxillary incisors. Eur $\mathrm{J}$ Orthodont 1998;20:427-434.

26. Maciel SP, Costa B, Gomide MR. Difference in the prevalence of enamel alterations affecting central incisors of children with complete unilateral cleft lip and palate. Cleft palate Craniofacial J 2005;42(4):392-395.

27. McDonagh S, Pinson R, Shaw AJ. Provision of general dental care for children with cleft lip and palate-parental attitudes and experiences. Br Dent J 2000:189;432-434.

28. McDonald $S$, Arkutu N, et al. Managing the paediatric patient with amelogenesis imperfecta. Br Dent J 2012;212(9):425-428.

29. McLaughlin WS. Congenital absence of all primary and permanent lateral incisors in a carrier of X-linked hypohydrotic ectodermal dysplasia. Int J Paed Dent 1991;2:99-103.

30. Ng FK, Messer LB. Dental management of amelogenesis imperfecta patients: a primer on genotupe-phenotype correlations. Pediatr Dent 2009;31:20-30.

31. Nivoloni Tannure $P$, et al. Prevalence of dental anomalies in nonsyndromic individuals with clefts lip and palate/ A systematic review and meta-analysis. Cleft palate Craniofacial J 2012;49(2):194-200.

32. Nivoloni Tannure $P$, de Castro Costa $M$, Calvano Küuchler $E$, et al. Caries experience in individuals with cleft lip and palate. Pediatr Dent 2012;34:127-31.

33. Noble J. Motivations of orthodontics residents in Canada and the United States to treat patients with craniofacial anomalies, cleft lip/palate, and special need. Cleft palate Craniofacial J 2012;49(5):596-600.

34. Nunn JH, Carter N, et al. The interdisciplinary management of hypodontia: background and role of paediatric dentistry. Brit Dent J 2003;194(5):245-251.

35. Nussbaum B, Carrel R. The behaviour modification of a dentally disabled child. J Dent Child 1976;43:255-261.

36. O'Connell A, Marini J. Evaluation of oral problems in an osteogenesis imperfecta population. Oral Surg Oral Med Oral Pathol Oral Radiol Endod 1999;87(2):189-96.

37. Opshal Vital S. Risque carieux et traitement orthodontique. International Orthodontics 2010;8:28-45.

38. Pegelow $M$, Alqadi $N$, et al. The prevalence of various dental characteristics in the primary and mixed dentition in patients born with non-syndromic unilateral cleft lip with or without cleft palate. Eur J Orthod 2012(34):561-570.

39. Poulsen S, Gjorup $H$, et al. Amelogenesis imperfecta: a systematic littérature review of associated dental and orofacial abnormalities and their impact on patients. Acta Odontol Scand 2008;66:193-9. 
40. Sapir S, Shapira Y. Dentinogenesis imperfecta: an early treatment strategy. Pediatr Dent $2001 ; 23: 232-7$.

41. Sapir S, Shapira J. Clinical solutions for developmental defects of enamel and dentin in children. Pediatr Dent 2007;29:330-6.

42. Saroglu O, Aras S, Oztas D. Effect of deproteinization on composite bond strength in hypocalcified amelogenesis imperfecta. Oral Dis 2006;12:305-308.

43. Sasaki Y, Kaida C, Saitoh I, et al. Craniofacial growth and functionnal change in oligodontia with ectodermal dysplasia: a case report. J Oral Rehab 2007;34;228-235.

44. Seow WK, Amaratunge FA. The effect of acid etching on enamel from different clinical variants of amelogenesis imperfecta: an SEM study. Pediatr Dent 1998;30:37-42.

45. Seow WK. Clinical diagnosis and management strategies of amelogenesis imperfecta variants. Pediatr Dent 1993;15:384-93.

46. Silva Dalben G, et al. Breast-feeding and sugar intake in babies with cleft lip and palate. Cleft Palate Craniofac J 2003;40(1):84-7.

47. Silva Dalben $G$, et al. Dental anesthetic procedures for cleft lip and palate patients. J Clin Pediatr Dent 2000;24(3):153-8.

48. Sundell S. Hereditary amelogenesis imperfecta: an epidemiologicical, genetic, and clinical study in a Swedish child population. Swed Dent J Suppl 1986;31:1-38.

49. Venezie RD, Vadiakas G, et al. Enamel pretreatment with sodium hypochlorite to enhance bonding in hypocalcified amelogenesis imperfecta: case report and SEM analysis. Pediatr Dent 1994;16:433-436.

50. Welbury RR, Murphy JM. The dental practitionner's role in protecting children from abuse. 2. The orofacial signs of abuse. Br Dent J 1998;24:61-5.

51. Wright J, Thornton J. Osteogenesis imperfecta with dentinogenesis imperfecta: a mistaken case of child abuse. Pediatr Dent 1983;5(3):207-9.

52. Wright JT, Deaton TC, Hall KI, et al. The mineral and protein content of enamel in amelogenesis imperfecta. Connect Tissue Res 1995;32:247-52.

53. Wright JT. The etch-bleach-seal technique for managing stained enamel defects in young permanent incisors. Pediatr Dent 2002;24:249-52. 